\title{
EFEK SERBUK KOPI ROBUSTA (Coffea canephora) TERHADAP PENYEMBUHAN LUKA INSISI PADA KELINCI (Oryctolagus cuniculus)
}

\author{
${ }^{1}$ Lilian N. Artho \\ ${ }^{2}$ Jane Wuisan \\ ${ }^{3}$ J. A. Najoan \\ ${ }^{1}$ Kandidat Skripsi Fakultas Kedokteran Universitas Sam Ratulangi Manado \\ ${ }^{2}$ Bagian Farmakologi Fakultas Kedokteran Universitas Sam Ratulangi Manado \\ Email: lilianartho@gmail.com
}

\begin{abstract}
Coffee is known as food and drink as well as alternative medicine for various types of wounds. One of the most coffee plants in Indonesia is Robusta coffee (Coffea canephora). This study aimed to determine whether Robusta coffee powder could accelerate the wound healing process. This was an experimental study using four rabbits as subjects. Incisions were made on the rabbit backs, right and left, with a length of $5 \mathrm{~cm}$. Wounds on the left backs, the untreated/control group, were only covered with sterile gauze. Wounds on the right backs, the treated group, were applied with robusta coffee powder and covered with sterile gauze. Robusta coffee powder and gauze were replaced two times a day. Wounds were macroscopically observed for 2 weeks. The results showed that at day 7, the wounds were still equally opened, dry, looked not too deep, and there was a crust on each wound surface. The lengths of the treated wounds were shorter than of the control wounds. At day 14, the edges of the treated wounds looked closer, the crusts were still attached to the wound surfaces and were smaller than of the control wounds. Conclusion: Robusta coffee powder (Coffea canephora) could accelerate the healing process of incised wounds on rabbit skin.
\end{abstract}

Keywords: wound healing, wound incision, robusta coffee powder, coffea canephora

\begin{abstract}
Abstrak: Kopi bukan hanya dikenal sebagai makanan dan minuman saja tetapi bisa juga sebagai obat alternatif dalam menangani berbagai jenis luka. Salah satu jenis tanaman kopi yang paling banyak di Indonesia ialah kopi Robusta (Coffea canephora). Penelitian ini bertujuan untuk menentukan apakah sebuk kopi robusta mempunyai efek untuk mempercepat proses penyembuhan luka. Penelitian ini menggunakan metode eksperimental dengan 4 ekor kelinci sebagai hewan coba. Luka insisi dibuat pada punggung kanan dan kiri kelinci dengan panjang $5 \mathrm{~cm}$. Luka pada punggung kiri merupakan luka kontrol yang tidak diberi perlakuan, hanya ditutupi dengan kasa steril. Luka pada punggung kanan merupakan luka perlakuan dengan diberi serbuk kopi robusta lalu ditutup kasa steril. Serbuk kopi robusta dan kasa diganti dua kali sehari. Pengamatan dilakukan selama 2 minggu dengan membandingkan gambaran makroskopik kedua luka. Hasil penelitian memperlihatkan pada hari ke 7 kedua luka masih sama-sama terbuka, kering, tampak sudah tidak terlalu dalam, dan terdapat kerak yang menempel pada permukaan luka. Ukuran luka perlakuan lebih pendek dari luka kontrol. Hari ke 14 kedua luka sudah mulai menutup, kerak masih menempel pada permukaan luka dan ukuran kerak luka perlakuan lebih kecil dari luka kontrol. Simpulan: Serbuk kopi robusta (Coffea canephora) memiliki efek untuk mempercepat penyembuhan luka insisi pada kulit kelinci.
\end{abstract}

Kata kunci: penyembuhan luka, luka insisi, kopi robusta, coffea canephora 
Kopi pertama kali ditemukan sekitar 1000 tahun SM sebagai tanaman liar di dataran tinggi Ethiopia, Afrika. ${ }^{1}$ Sejarah kopi di Indonesia berawal dari seorang Gubernur Belanda di Malabar yang mengirimkan bibit kopi arabika kepada Gubernur Belanda di Batavia, namun bibit Arabika pertama yang dikirimkan tersebut gagal tumbuh akibat banjir hebat melanda Batavia. $^{2}$

Secara umum dikenal 4 jenis kopi, yaitu kopi arabika (coffea arabica), kopi liberika (coffea liberica), kopi robusta (coffea canephora), dan kopi excelsa (coffea dewevrei). Kopi arabika memiliki kualitas tinggi dan beraroma harum. Kualitas robusta berada di bawah arabika, cenderung berasa asam dan pahit, serta kandungan kafein yang lebih tinggi (2-3 kali) dari arabika. ${ }^{1}$

Disamping rasa dan aromanya, kopi mempunyai banyak kandungan yang berguna untuk tubuh, salah satunya kafein yang berguna dalam penekanan pertumbuhan sel kanker. Kafein juga berfungsi dalam menurunkan resiko diabetes melitus tipe 2 (dengan cara menjaga sensibilitas tubuh terhadap insulin), penyakit Parkinson, dan juga Alzheimer. Kopi mengandung lebih banyak antioksidan daripada buah dan sayuran. Beberapa senyawa antioksidan yang terdapat di dalam kopi di antaranya polifenol, flavonoid, proantisianidin, kumarin, asam klorogenat, trigonelin dan tokoferol. ${ }^{1,3}$ Kopi bukan hanya dikenal sebagai makanan dan minuman saja.

Banyak bukti empiris yang menyatakan bahwa masyarakat Indonesia ternyata telah lama menggunakan serbuk kopi murni sebagai obat alternatif dalam menangani berbagai jenis luka yang di karenakan oleh benda tajam maupun benda tumpul pada kulit. Luka adalah hilang atau rusaknya sebagian jaringan tubuh akibat kekerasan atau trauma. Keparahan luka tergantung dari besarnya trauma yang diterima oleh jaringan. ${ }^{4}$ Pada dasarnya proses penyembuhan luka pada setiap jenis luka itu sama. Walaupun proses tersebut terjadi secara spontan dan menimbulkan reaksi yang kompleks tetapi proses ini tetap terjadi secara teratur dari fase inflamasi, fase proliferasi, dan remodeling jaringan. ${ }^{5}$ Dr. Hendro Sudjono Yuwono MD, Ph.D, ahli bedah pembuluh darah dari RS Hasan Sadikin, Bandung ini sudah melakukan serangkaian penelitian terhadap kopi sejak awal tahun 2004 dan hasil penelitiannya menunjukkan bahwa kopi dapat digunakan untuk mengatasi berbagai jenis luka, mulai dari luka tergores benda tajam, luka bakar, sampai luka koreng yang sudah terinfeksi. Dalam penelitiannya, Dr. Hendro menemukan zat antibakteri dalam serbuk kopi yang belum diketahui secara pasti jenis kandungannya, namun zat ini terbukti efektif membasmi kuman Methicillin Resistant Starhylococcus Aureus (MRSA) yang sering dijumpai pada luka bernanah. ${ }^{1}$

\section{METODE PENELITIAN}

Penelitian ini menggunakan metode eksperimental. Penelitian dilakukan di Laboratorium Farmakologi Fakultas Kedokteran Universitas Sam Ratulangi pada bulan September 2012 sampai bulan Januari 2013. Variabel yang digunakan merupakan variabel bebas dan variabel terikat.

Hewan uji terdiri dari 4 ekor kelinci dewasa. Pada punggung kanan dan kiri masig-masing kelinci dibuat luka insisi dengan panjang $5 \mathrm{~cm}$. Luka pada punggung kiri tidak diberi serbuk kopi robusta dan hanya ditutupi kain kasa steril untuk melihat penyembuhan luka secara alamiah. Luka pada punggung kanan diberi serbuk kopi robusta sebanyak 1 sendok teh sehari dua kali, yaitu pada pagi dan sore hari. Serbuk kopi robusta diberikan secara merata pada punggung sebelah kanan dan ditutupi kain kasa steril. Panjang dan lebar luka kontrol dan luka perlakuan diamati setiap hari. Setiap penggantian serbuk kopi, luka pada punggung kanan dan kiri dibersihkan menggunakan aquades yang disemprotkan dengan menggunakan dispo secara perlahan, kemudian dikeringkan dengan menekan kain kasa steril secara perlahan di kedua luka tersebut. Pengamatan dilakukan selama 2 minggu. 


\section{HASIL PENELITIAN}

Hasil penelitian merupakan gambaran makroskopik penyembuhan luka pada kulit kelinci. Pada hari pembuatan luka, dibuat luka insisi pada kedua punggung kelinci dengan panjang luka $5 \mathrm{~cm}$ dan kedalaman $0,3 \mathrm{~cm}$. Terlihat kedua luka tersebuat mengeluarkan banyak darah sebagai respon terhadap cedera (Gambar 3). Sesaat setelah itu, luka pada punggung sebelah kanan langsung diberikan serbuk kopi robusta (Gambar 4), kemudian kedua luka tersebut ditutupi kain kasa steril.

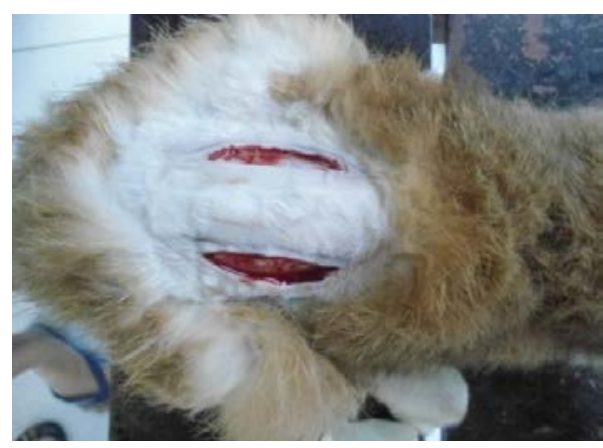

Gambar 3. Luka insisi yang baru dibuat (H-1)

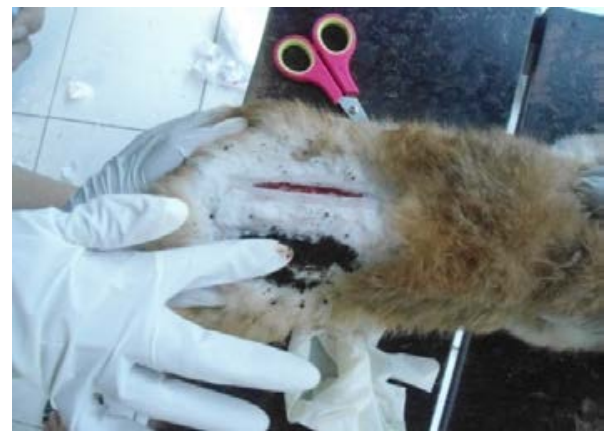

Gambar 4. Luka diberi serbuk kopi robusta $(\mathrm{H}-1)$

Pada pengamatan hari ke-4, kedua luka pada kulit kelinci sama-sama masih terbuka dan terlihat ada selaput tipis berwarna kuning pucat yang melapisi bagian permukaan luka. Pada luka yang diberi serbuk kopi robusta (Gambar 5) menunjukkan sedikit perbedaan, yaitu selaput tipis yang melapisi luka telah mengering dan panjang luka lebih pendek $1,5 \mathrm{~cm}$ dari luka tanpa serbuk kopi robusta
(Gambar 6). Luka tanpa serbuk kopi robusta berwarna kemerahan di bagian pinggir luka dan permukaan luka tampak agak pucat, sedangkan luka dengan serbuk kopi robusta terlihat berwarna hitam karena tertutup dengan sisa serbuk kopi robusta yang telah mengering.

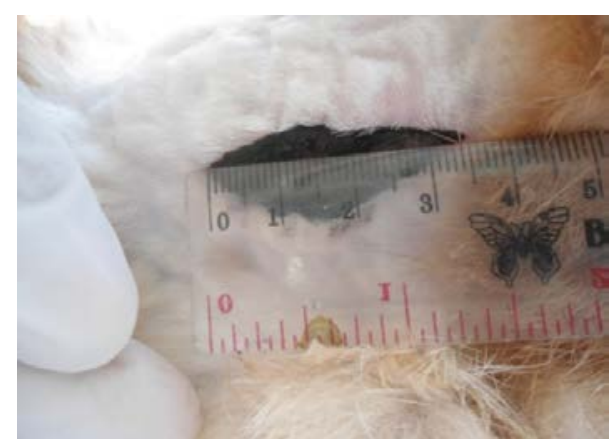

Gambar 5. Luka dengan serbuk kopi robusta (H-4)

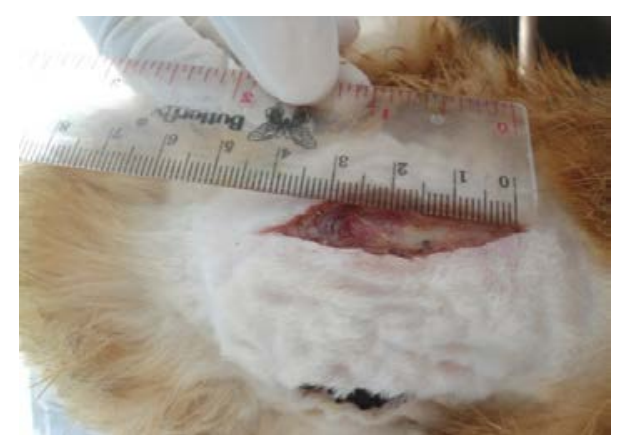

Gambar 6. Luka tanpa serbuk kopi robusta (H4)

Pada pengamatan hari ke-7 kedua luka masih sama-sama terbuka, luka telah kering, tampak sudah tidak terlalu dalam, dan terdapat kerak yang menempel pada permukaan luka. Luka yang diberi serbuk kopi robusta (Gambar 7) memperlihatkan kerak berwarna hitam yang terbentuk akibat menempelnya sisa serbuk kopi yang mengering dan ukuran luka lebih pendek jika dibandingkan dengan luka tanpa serbuk kopi robusta (Gambar 8). Luka tanpa serbuk kopi robusta terlihat merah pucat pada bagian dalam luka. 


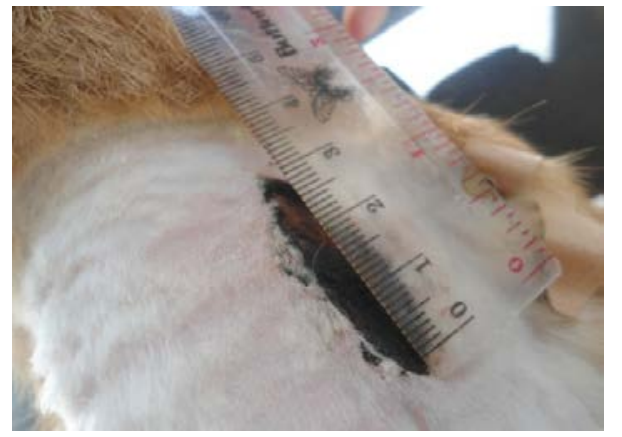

Gambar 7. Luka dengan serbuk kopi robusta (H-7)

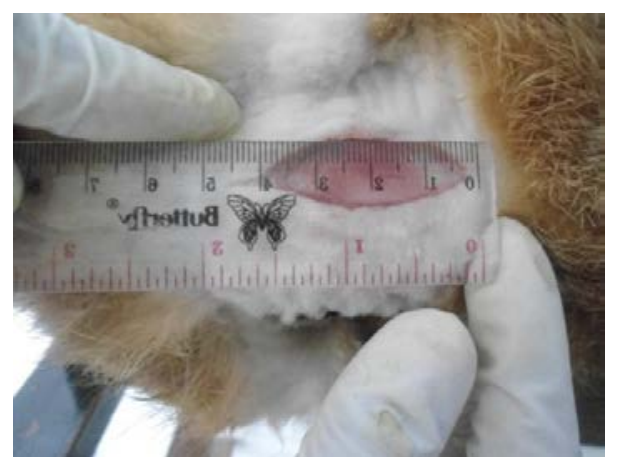

Gambar 8. Luka tanpa serbuk kopi robusta (H7)

Pada pengamatan hari ke-14 kedua luka terlihat sudah mulai menutup, kerak masih menempel pada kedua luka, ukuran kerak mengecil, dan tampak permukaan luka sudah menyatu dengan kulit sekitar. Kerak pada luka dengan serbuk kopi robusta berwarna hitam (Gambar 9), sedangkan luka tanpa serbuk kopi robusta memiliki kerak berwarna merah muda (Gambar 10). Kedua kerak sama-sama belum terlepas dari kulit kelinci. Dalam hal ini, luka dapat dikatakan sudah sembuh karena permukaan luka sudah mulai menyatu dengan kulit kelinci (kedalaman 0 ) hanya tinggal menunggu masing-masing kerak terlepas dengan sendirinya. Yang diukur adalah panjang kerak luka. Panjang kerak luka kontrol 2,7 cm dan panjang kerak luka perlakuan $1 \mathrm{~cm}$. Hasil perbandingan antara luka kontrol dan luka perlakuan dapat dilihat pada tabel 1 dan grafik pada Gambar 11, 12, 13, dan 14.

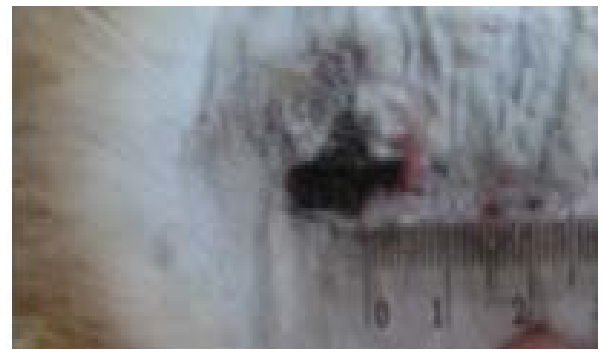

Gambar 9. Luka dengan serbuk kopi robusta (H-14)

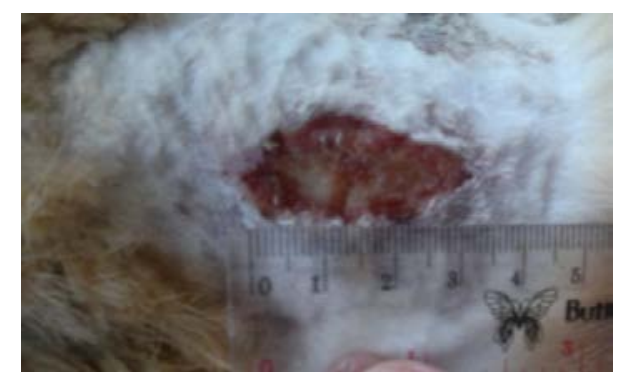

Gambar 10. Luka tanpa serbuk kopi robusta (H-14)

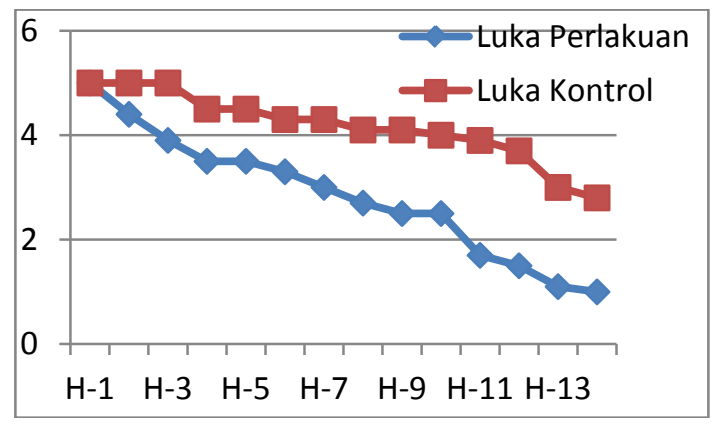

Gambar 11. Grafik hasil pengamatan ukuran panjang luka pada punggung kelinci A mulai dari $\mathrm{H}-1$ sampai pada $\mathrm{H}-14$

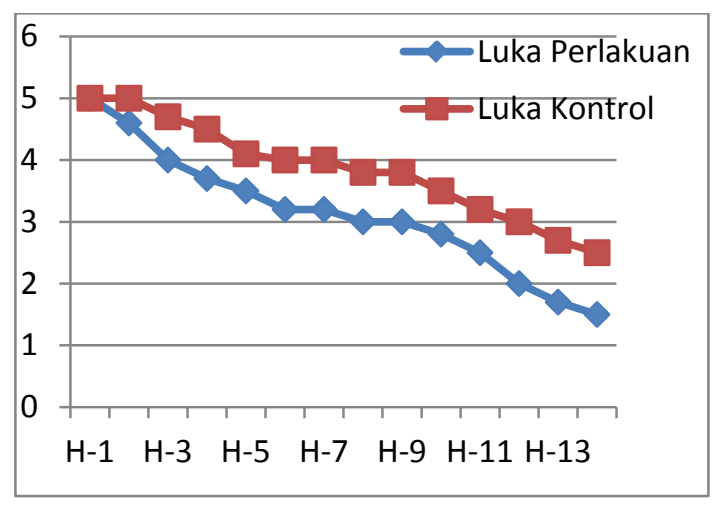

Gambar 12. Grafik hasil pengamatan ukuran panjang luka pada punggung kelinci B mulai dari H-1 sampai pada $\mathrm{H}-14$ 


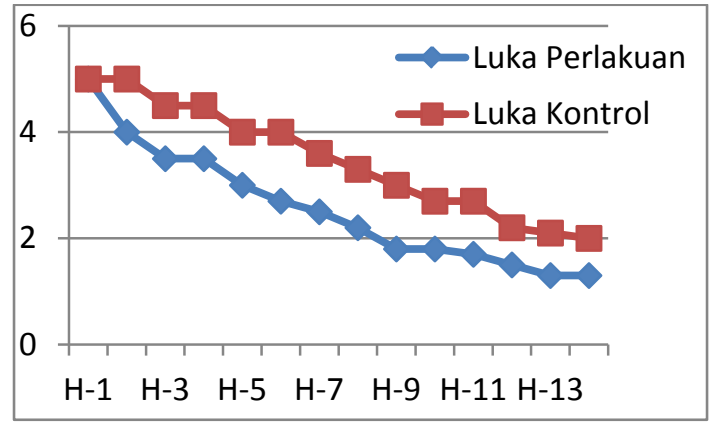

Gambar 13. Grafik hasil pengamatan ukuran panjang luka pada punggung kelinci C mulai dari H-1sampai pada $\mathrm{H}-14$

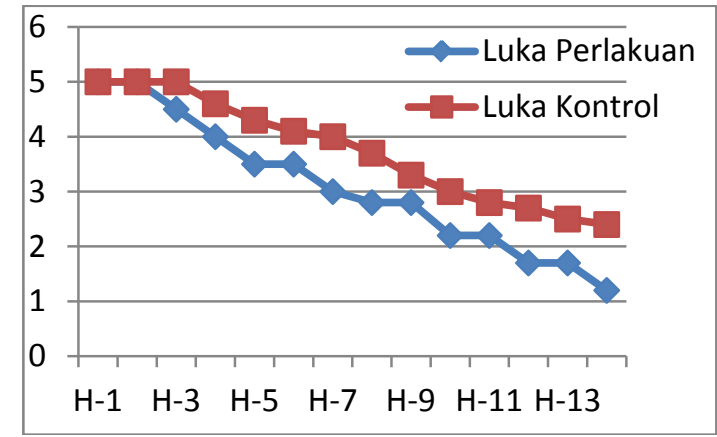

Gambar 14. Grafik hasil pengamatan ukuran panjang luka pada punggung kelinci D mulai dari $\mathrm{H}-1$ sampai pada $\mathrm{H}-14$

Tabel 1. Perbandingan hasil pengamatan ukuran luka kulit kelinci

\begin{tabular}{|c|c|c|c|c|c|c|c|c|c|c|c|c|c|c|c|c|}
\hline \multirow{3}{*}{$\begin{array}{l}\text { Hari } \\
\text { ke }\end{array}$} & \multicolumn{4}{|c|}{ Kelinci A } & \multicolumn{4}{|c|}{ Kelinci B } & \multicolumn{4}{|c|}{ Kelinci C } & \multicolumn{4}{|c|}{ Kelinci D } \\
\hline & \multicolumn{2}{|c|}{ Panjang } & \multicolumn{2}{|c|}{ Lebar } & \multicolumn{2}{|c|}{ Panjang } & \multicolumn{2}{|c|}{ Lebar } & \multicolumn{2}{|c|}{ Panjang } & \multicolumn{2}{|c|}{ Lebar } & \multicolumn{2}{|c|}{ Panjang } & \multicolumn{2}{|c|}{ Lebar } \\
\hline & Kiri & Kanan & Kiri & Kanan & Kiri & Kanan & Kiri & Kanan & Kiri & Kanan & Kiri & Kanan & Kiri & Kanan & Kiri & Kanan \\
\hline 0 & 5 & 5 & 1 & 1 & 5 & 5 & 0,9 & 1 & 5 & 5 & 1,2 & 1 & 5 & 5 & 1 & 1 \\
\hline 1 & 5 & 5 & 1 & 1 & 5 & 5 & 0,9 & 1 & 5 & 5 & 1,2 & 1 & 5 & 5 & 1 & 1 \\
\hline 2 & 5 & 4,4 & 1 & 1 & 5 & 4,6 & 0,9 & 0,8 & 5 & 4 & 1,2 & 1 & 5 & 5 & 1 & 0,9 \\
\hline 3 & 5 & 3,9 & 1 & 1 & 4,7 & 4 & 0,8 & 0,6 & 4,5 & 3,5 & 1,1 & 0,9 & 5 & 4,5 & 2,1 & 0,9 \\
\hline 4 & 4,5 & 3,5 & 1,4 & 0,9 & 4,5 & 3,7 & 1 & 0,6 & 4,5 & 3,5 & 1 & 0,9 & 4,6 & 4 & 1,4 & 0,8 \\
\hline 5 & 4,5 & 3,5 & 1 & 0,9 & 4,1 & 3,5 & 1 & 0,5 & 4 & 3 & 1,1 & 1 & 4,3 & 3,5 & 1,8 & 0,5 \\
\hline 6 & 4,3 & 3,3 & 1 & 0,8 & 4 & 3,2 & 1,1 & 0,7 & 4 & 2,7 & 1,2 & 1 & 4,1 & 3,5 & 2,1 & 0,5 \\
\hline 7 & 4,3 & 3 & 1 & 1 & 4 & 3,2 & 1,5 & 0,7 & 3,6 & 2,5 & 1,5 & 0,8 & 4 & 3 & 2 & 1 \\
\hline 8 & 4,1 & 2,7 & 1,3 & 0,7 & 3,8 & 3 & 1,5 & 0,8 & 3,3 & 2,2 & 1,7 & 0,8 & 3,7 & 2,8 & 1,9 & 1 \\
\hline 9 & 4,1 & 2,5 & 1,1 & 0,5 & 3,8 & 3 & 1,5 & 1 & 3 & 1,8 & 1,7 & 0,7 & 3,3 & 2,8 & 1,9 & 0,7 \\
\hline 10 & 4 & 2,5 & 1,7 & 0,5 & 3,5 & 2,8 & 1,4 & 1 & 2,7 & 1,8 & 1,7 & 0,7 & 3 & 2,2 & 1,8 & 0,7 \\
\hline 11 & 3,9 & 1,7 & 1,9 & 0,6 & 3,2 & 2,5 & 1,4 & 0,9 & 2,7 & 1,7 & 1,6 & 0,8 & 2,8 & 2,2 & 1,7 & 0,6 \\
\hline 12 & 3,7 & 1,5 & 1 & 0,4 & 3 & 2 & 1,5 & 0,9 & 2,2 & 1,5 & 1.5 & 0,8 & 2,7 & 1,7 & 1,7 & 0,6 \\
\hline 13 & 3 & 1,1 & 0,8 & 0,3 & 2,7 & 1,7 & 1,5 & 0,8 & 2,1 & 1,3 & 1,5 & 0,6 & 2,5 & 1,7 & 1,5 & 0,5 \\
\hline 14 & 2,8 & 1 & 0,7 & 0,2 & 2,5 & 1,5 & 1,5 & 0,8 & 2 & 1,3 & 1,5 & 0,6 & 2,4 & 1,2 & 1,1 & 0,5 \\
\hline
\end{tabular}

Ket: Kiri $\quad$ : Luka kontrol (tanpa perlakuan)

Kanan : Luka perlakuan (dengan serbuk kopi robusta)

\section{BAHASAN}

Penelitian ini bertujuan untuk melihat efek dari pemberian serbuk kopi robusta terhadap waktu penyembuhan luka insisi terbuka pada kulit kelinci dengan melihat perbedaan makroskopik antara luka yang diberi serbuk kopi robusta dengan luka tanpa pemberian serbuk kopi robusta.

Luka yang diberi serbuk kopi robusta adalah luka pada punggung bagian kanan sedangkan luka pada punggung kiri tidak diberikan apa-apa. Kedua luka kemudian ditutup dengan kain kasa steril. Luka pada punggung sebelah kiri akan dijadikan sebagai pembanding antara penyembuhan luka secara alami pada luka kontrol dengan penyembuhan luka menggunakan serbuk kopi robusta pada luka perlakuan. Pada hari pembuatan luka, dibuat luka insisi sepanjang $5 \mathrm{~cm}$ dan kedalaman $0,3 \mathrm{~cm}$ pada punggung kelinci. Terlihat banyak darah yang keluar dari luka (Gambar 3) sebagai tanda bahwa kulit mengalami cedera akibat putusnya pembuluh darah, dan tubuh berusaha menghentikannya dengan cara vasokonstriksi, pengerutan pembuluh darah yang terputus (retraksi), dan reaksi hemotasis. Hemostasis terjadi karena keluarnya trombosit, trombosit mengeluarkan prostaglandin, tromboksan, bahan kimia tertentu dan asam amino tertentu yang mempengaruhi pembekuan darah, mengatur tonus dinding pembuluh darah dan kemotaksis terhadap leukosit. Pemberian serbuk kopi robusta dan kain kasa steril dalam hal ini juga membantu 
menghalangi keluarnya darah secara berlebihan.

Pada hari ke-4, kedua luka pada kulit kelinci sama-sama masih terbuka, pada luka yang diberi serbuk kopi robusta permukaan luka telah mengering sedangkan luka yang tidak diberi serbuk kopi robusta masih agak basah dan masih ada selaput tipis yang melapisi bagian permukaan luka. Luka tanpa pemberian serbuk kopi robusta terlihat masih kemerahan (Gambar 6). Hal ini menunjukkan bahwa luka kelinci pada punggung kiri sedang mengalami proses peradangan yang merupakan fase awal dari penyembuhan luka. Luka yang diberikan serbuk kopi robusta (Gambar 5) tidak nampak kemerahan karena tertutupi oleh sisa serbuk kopi robusta yang mengering dan menempel pada luka. Proliferasi fibroblast sedang terjadi pada kedua luka tersebut, hal ini dapat dilihat dari panjang luka yang mulai memendek dari ukuran semula $(5 \mathrm{~cm})$ menjadi $4,5 \mathrm{~cm}$ (luka kontrol) dan 3,5 cm (luka perlakuan).

Pada hari ke-7 kedua luka sama-sama masih terbuka, sudah kering dan terbentuk kerak yang menutupi permukaan luka. Kerak pada luka yang diberi serbuk kopi robusta terlihat hitam (Gambar 7). Hal ini disebabkan oleh karena sisa serbuk kopi robusta yang mengering dan menempel pada permukaan luka, sedangkan luka tanpa serbuk kopi robusta (Gambar 8) terdapat kerak berwarna kuning dan bagian pinggir luka berwarna kemerahan pucat. Pada hari ke-7 ukuran luka menjadi $4 \mathrm{~cm}$ (luka kontrol) dan $3 \mathrm{~cm}$ (luka perlakuan). Pada fase ini, serat kolagen dibentuk dan dihancurkan kembali untuk menyesuaikan tegangan pada luka yang cenderung mengkerut. Sifat ini, bersama dengan sifat kontraktil miofibroblast yang menyebabkan tarikan pada tepi luka. Kedua luka sudah tidak terlalu dalam karena epitel tepi luka yang terdiri atas sel basal terlepas dari dasarnya dan berpindah mengisi permukaan luka.

Pada hari ke-14 luka sudah menunjukan perbaikan. Kedua pinggiran luka sudah mulai menyatu dengan kulit sekitar dan permukaan luka sudah sejajar dengan kulit. Luka kontrol (Gambar 10) terlihat cerah daripada luka perlakuan (Gambar 9) yang ditutupi oleh kerak berwarna hitam. Kerak yang berwarna hitam ini ialah serbuk kopi robusta yang telah mengering dan tertempel menutupi luka. Pada saat ini fase proliferasi masih terjadi dan akan memasuki fase remodeling. Kerak pada permukaan kulit kelinci belum terlepas. Faktor yang diduga turut berperan sehingga kerak pada permukaan luka belum terlepas dan luka belum sembuh sempurna saat minggu ke-2 adalah adanya sisa serbuk kopi robusta yang mengering dan menempel di permukaan luka yang dianggap sebagai benda asing oleh tubuh. Faktor yang tidak dapat disingkirkan di atas diduga menghalangi pematangan permukaan luka sehingga kerak belum terlepas dari kulit kelinci.

\section{SIMPULAN}

Serbuk kopi robusta (Coffea canephora) memiliki efek untuk mempercepat penyembuhan luka insisi pada kulit kelinci.

\section{DAFTAR PUSTAKA}

1. Redaksi Health Secret. Khasiat Bombastis Kopi. Jakarta: Elex Media Komputindo, 2012; p. 13, 22-23, 2729, 37, 97, 128-9.

2. Sejarah Kopi Indonesia. [cited 2012 Oct 23]. Available from: http://www. bironk.com/sejarah-kopi/.

3. Sani A. Manfaat Kopi untuk Kesehatan. [cited 2012 Oct 23]. Available from: http://dokter-herbal.com/manfaatkopi-untuk-kesehatan.html.

4. Sjamsuhidajat, R. dan De Jong, W. BukuAjar Ilmu Bedah. Jakarta: EGC, 2005; p. 14, 67-76.

5. Kumar, Cotran, Robbins. Buku Ajar Patologi Robbins (Edisi 7). Jakarta: EGC, 2007; p.35, 65-78, 80-82. 